\title{
Exercise-based interventions and C-reactive protein in overweight and obese youths: a meta-analysis of randomized controlled trials
}

\author{
Antonio García-Hermoso ${ }^{1}$, Mairena Sánchez-López ${ }^{2,3}$, Yolanda Escalante ${ }^{4}$, Jose M. Saavedra ${ }^{5}$ and Vicente Martínez-Vizcaíno²
}

BACKGROUND: One of the most commonly measured markers of inflammation in clinical settings is C-reactive protein (CRP). The purpose of this meta-analysis was to examine the evidence for the effectiveness of physical exercise interventions on modifying the levels of serum CRP in children and adolescents with excess of weight.

METHODS: Two independent reviewers assessed articles from seven databases. Studies were limited to physical exercise interventions in children and adolescents diagnosed as overweight or obese, and including a comparison control group. Weighted mean difference (WMD) was calculated using random-effects model and potential moderators were explored (i.e., weight status, ages, duration of study, frequency of exercise per week, and duration of session). The heterogeneity of the studies was estimated using Cochran's Q-statistic and $R$.

RESULTS: Nine randomized controlled trials met the inclusion criteria ( $n=427$ youths). Overall, results suggest a nonsignificant trend toward a reduction CRP levels (WMD $=-0.72 \mathrm{mg} / \mathrm{l}$; 95\% confidence interval: -1.52 to $0.08 ; P=0.077$ ). Also, there were not significant moderators of exercise effects on CRP.

CONCLUSION: These results suggest that exercise programs in children and adolescents not mitigate the inflammatory effects of excess weight, although there was a trend toward reduction.

$\mathbf{T}$ he prevalence of obesity among children and adolescents has dramatically increased in recent decades (1). Several physiopathologic mechanisms linking obesity to cardiovascular risk have been described (2). Inflammation is considered an important pathogenic mechanism in both the initiation and progression of cardiovascular diseases (CVD) (3). One of the most commonly measured markers of inflammation in clinical settings is C-reactive protein (CRP) $(4,5)$. Plasma levels of CRP have been reported to be a strong independent predictor of risk of future myocardial infarction, stroke, peripheral arterial disease, and vascular death among individuals without known CVD (4). On the other hand, obesity has been associated with elevated levels of CRP in both adults and children (6). Furthermore, elevated levels of inflammatory factors in childhood and adolescence have been shown to track into adulthood (7). Given the apparent importance of CRP among other inflammatory markers in the development of CVD morbidity and mortality, it is critical to determine those factors that may help to lower and maintain optimal levels of CRP (8).

It is documented that physical activity has a role in preventing CVD (9), mediated, in part, by changes in inflammation. Recently, great attention has been focused on the response of inflammation to physical exercise. Several studies have not provided support for exercise intervention-induced reductions in CRP in adults $(8,10)$ and children (11). A recent review, although concluding that assessing body composition distribution may assist in interpreting the effectiveness of interventions in improving circulating inflammatory markers in obese children (3), does not provide enough evidence about the effect of physical exercise on reducing CRP levels. In contrast, other studies concluded that habitual physical exercise results in lower levels of CRP $(10,12)$. Therefore, evidence about the impact of physical exercise on controlling the inflammation process is not clear, and a meta-analysis of randomized controlled trial (RCT) to establish evidence in this regard seems timely.

The purpose of this meta-analysis was to examine the evidence for the effectiveness of exercise interventions on modifying the levels of serum CRP in overweight and/or obese youths.

\section{RESULTS}

\section{Study Selection}

A total of 447 potentially relevant articles were identified. Of these, 292 were discarded because it was clear from the abstracts they did not meet the inclusion criteria and 109 were duplicates. The full text of the remaining 46 candidates was then examined. Of these, 37 were rejected-9 for failing the subjects' profile criterion, 10 for the study design criterion (no $\mathrm{RCT}$ ), 15 for the type of intervention criterion (interventions

\footnotetext{
'Laboratorio de Ciencias de la Actividad Física, el Deporte y la Salud, Facultad de Ciencias Médicas, Universidad de Santiago de Chile, USACH, Santiago, Chile; ${ }^{2} \mathrm{Health}$ and Social Research Center, Universidad de Castilla-La Mancha, Cuenca, Spain; ${ }^{3}$ School of Education, University of Castilla-La Mancha, Ciudad Real, Spain; ${ }^{4}$ Facultad de Ciencias del Deporte, AFIDES Research Group, Universidad de Extremadura, Cáceres, Spain; ${ }^{5}$ Physical Activity, Physical Education, Sport and Health Research Centre, Sports Science Department, School of Science and Engineering, Reykjavik University, Reykjavik, Iceland. Correspondence: Antonio García-Hermoso (antonio.garcia.h@usach.cl) 
with diet, education, nutrition, or drug), 2 did not determine CRP, and 1 used the same sample. This left nine studies meeting the inclusion criteria that were used for the meta-analysis (Figure 1).

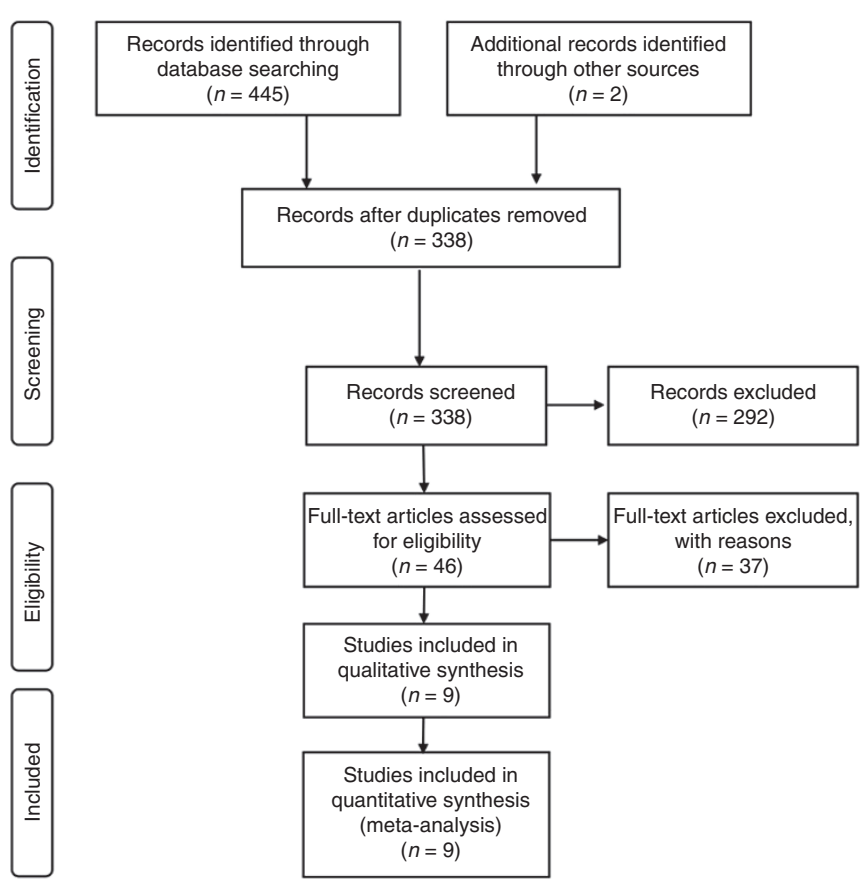

Figure 1. Preferred Reporting Items for Systematic Reviews and MetaAnalyses (PRISMA) flowchart of the study selection process.

\section{Study Characteristics and Interventions}

The characteristics of the nine studies $(11,13-20)$ are listed in Table 1 ( $n=219$ and $n=208$, subjects in intervention and control groups, respectively).

\section{Participants}

The analysis included a total of 427 youths. Two studies included only boys $(15,20)$ and one only girls $(18)$, and the remaining studies included both boys and girls $(11,13,14,16,17,19)$. Participants in four studies were children $(14,16,17,20)$, in four adolescents $(13,15,18,19)$, and in the other both age groups (11). Several criteria were used to define overweight and obesity: in one study, the 85th BMI percentile was used $(13,17)$, another study used WHO criteria (19), three studies used Korean $(18)$ and German $(14,16)$ nation-specific criteria for the juvenile population, and the other three studies did not provide any reference for the criterion they used for the classification $(11,15,20)$ (Table 1$)$.

\section{Physical Exercise Program Characteristics}

The main content of the programs was based on multiperson sports with games such as soccer (19), basketball, and handball $(14,20)$, athletic (running) (16), and aquatic activities such as swimming and water games (20). Other studies used stationary cycling $(11,13)$, dance $(17)$, walking $(14,16,18,20)$, and skipping rope (15). In two studies, part of each session was devoted to strength training, using either the person's own body weight or elastic bands (14,20). All the studies included stretching and flexibility exercises. The program structure was

Table 1. Characteristics of the studies included in the meta-analysis

\begin{tabular}{|c|c|c|c|c|c|c|c|c|c|c|c|c|c|}
\hline \multirow[b]{2}{*}{ Study } & \multicolumn{3}{|c|}{ EG } & \multicolumn{3}{|c|}{ CG } & \multirow{2}{*}{$\begin{array}{c}\text { BMI } \\
\text { (percentile } \\
\text { or kg/m²) }\end{array}$} & \multicolumn{5}{|c|}{ Intervention characteristics } & \multirow[b]{2}{*}{$\begin{array}{l}\text { Delphi } \\
\text { score }\end{array}$} \\
\hline & $n$ & Age $(y)^{a}$ & Type & $n$ & Age (y) & Type & & $\begin{array}{l}\text { Duration } \\
\text { (wk) }\end{array}$ & $\begin{array}{c}\text { Frequency } \\
\text { (Se/wk) }\end{array}$ & $\begin{array}{l}\text { Se duration } \\
\text { (min) }\end{array}$ & Intensity & $\begin{array}{c}\text { Compliance } \\
(\%)\end{array}$ & \\
\hline $\begin{array}{l}\text { Alberga } \\
\text { et al. (13) }\end{array}$ & 74 & $15.5(1.4)$ & Machines & 74 & $15.6(1.3)$ & None & $\geq 85 p$ & 22 & 2 & $20-40$ & $70-85 \%{ }^{c}$ & 62 & 6 \\
\hline $\begin{array}{l}\text { Farpour- } \\
\text { Lambert } \\
\text { et al. (14) }\end{array}$ & 22 & $9.1(1.4)$ & Multisports & 22 & $8.8(1.6)$ & None & $\geq 97 p$ & 12 & 3 & 60 & $55-65 \%{ }^{c}$ & 83 & 6 \\
\hline $\begin{array}{l}\text { Kelly } \\
\text { etal. (11) }\end{array}$ & 9 & $10.8(0.67)$ & $\begin{array}{l}\text { Stationary } \\
\text { cycling }\end{array}$ & 10 & $11.0(0.71)$ & None & $\geq 85 p$ & 8 & 4 & 30 & $50-60 \%{ }^{c}$ & NR & 4 \\
\hline $\begin{array}{l}\text { Kim } \\
\text { etal. (15) }\end{array}$ & 14 & $17.0(0.11)$ & Skipping rope & 12 & $16.8(0.13)$ & None & NR & 6 & 5 & 40 & NR & NR & 4 \\
\hline $\begin{array}{l}\text { Meyer } \\
\text { etal. (16) }\end{array}$ & 33 & $13.7(2.1)$ & Multisports & 34 & $14.7(2.2)$ & None & $\geq 97 p$ & 24 & 3 & $60-90$ & NR & NR & 4 \\
\hline $\begin{array}{l}\text { Murphy } \\
\text { etal. (17) }\end{array}$ & 23 & $7-12$ & Dance & 12 & $7-12$ & None & $\geq 85 p$ & 12 & 5 & $10-30$ & NR & 75 & 3 \\
\hline $\begin{array}{l}\text { Park } \\
\text { etal. (18) }\end{array}$ & 22 & $14.2(0.5)$ & Walking & 22 & $14.1(0.5)$ & None & $\geq 95 p$ & 12 & 6 & $30-40$ & $55-75 \%{ }^{d}$ & 82 & 4 \\
\hline $\begin{array}{l}\text { Vasconcellos } \\
\text { etal. (19) }\end{array}$ & 10 & $14.1(1.3)$ & Soccer & 10 & $14.8(1.4)$ & None & $>2 \mathrm{SD}^{\mathrm{b}}$ & 12 & 3 & 60 & NR & NR & 5 \\
\hline $\begin{array}{l}\text { Wong } \\
\text { et al. (20) }\end{array}$ & 12 & $13.7(1.1)$ & $\begin{array}{l}\text { Machines + } \\
\text { multisports }\end{array}$ & 12 & $14.2(1.5)$ & None & $>25$ & 12 & 2 & $45-62$ & $65-85 \%{ }^{d}$ & NR & 4 \\
\hline
\end{tabular}

CG, control group; EG, experimental group; None, no intervention; NR, not reported; p, percentile; Se, session.

a Data were presented as the mean value (SD) or range. ${ }^{\mathrm{B} M M I}>2$ SDs above age- and sex-specific WHO reference medians. ${ }^{c}$ Maximal heart rate. ${ }^{\mathrm{d}} \mathrm{Maximal}$ oxygen consumption. 


\section{Systematic Review}

very different in terms of duration: most of them lasted $12 \mathrm{wk}$ (14,17-20) and included four 30-min sessions by week (11). Finally, only four studies reported compliance $(13,14,17,18)$, and all of them exceeded $75 \%$ except one which reported a lower adherence (13).

\section{CRP Assessments}

All the techniques employed to determine CRP used ultrasensitive methods: nephelometry $(11,14)$, latex-enhanced immunoturbidimetric assay $(15,19)$, immunoradiometry assay $(13,17,18)$, and highly sensitive enzyme-linked immunosorbent assay (20). Finally, only one study did not provide the method for determining CRP levels (16).

\section{Primary Outcome (Change in CRP)}

Table 2 lists the values for each variable in all the studies preand postintervention. Figure 2 summarizes these results. The weighted mean difference (WMD) and 95\% confidence interval (CI) were calculated for each study. There were not quite significant decreases in CRP levels (WMD $=-0.72 \mathrm{mg} / \mathrm{l} ; 95 \%$ CI: -1.52 to $0.08 ; P=0.077$ ) (Figure 2), with large inconsistency $\left(I^{2}=69 \%\right)(21)$.

Table 2. Values of pre- and posttest (mean and SD) and WMD for C-reactive protein $(\mathrm{mg} / \mathrm{l})$ in the programs

\begin{tabular}{lcccccr}
\hline & \multicolumn{2}{c}{ Pretest } & & \multicolumn{2}{c}{ Posttest } & \\
\cline { 2 - 3 } & EG & CG & & EG & CG & WMD \\
\hline Alberga et al. (13) & $2.6(2.8)$ & $2.2(2.4)$ & & $2.2(2.7)$ & $1.9(2.4)$ & 0.25 \\
Farpour-Lambert et al. (14) & $3.4(5.3)$ & $4.7(4.2)$ & $3.3(7.0)$ & $4.6(5.6)$ & -1.30 \\
Kelly et al. (11) & $4.4(4.8)$ & $5.0(3.8)$ & $4.8(7.8)$ & $3.8(2.8)$ & 1.00 \\
Kim et al. (15) & $1.7(0.5)$ & $0.9(0.7)$ & $1.0(0.6)$ & $2.1(0.7)$ & -1.10 \\
Meyer et al. (16) & $4.8(6.3)$ & $4.6(0.5)$ & $2.1(2.4)$ & $3.4(4.8)$ & -1.30 \\
Murphy et al. (17) & $3.1(2.9)$ & $4.7(2.7)$ & $2.6(7.1)$ & $4.8(2.6)$ & -2.20 \\
Park et al. (18) & $1.0(1.0)$ & $0.8(0.5)$ & $0.9(0.7)$ & $1.1(0.8)$ & -0.20 \\
Vasconcellos et al. (19) & $4.3(3.2)$ & $3.9(1.3)$ & $3.7(1.8)$ & $4.1(2.3)$ & -0.40 \\
Wong et al. (20) & $3.1(1.4)$ & $3.4(2.4)$ & $4.1(5.0)$ & $4.3(3.5)$ & -0.20 \\
\hline \multicolumn{2}{l}{ Data were presented as the mean value (SD). } & & & & \\
EG, experimental group; CG, control group; WMD, weighted mean difference. &
\end{tabular}

\section{Subgroup Analyses (Moderator Effects)}

Weight status (overweight, $P=0.881$; obese, $P=0.109$ ), ages (children, $P=0.380$; adolescents, $P=0.123$ ), duration of study ( $<12 \mathrm{wk}, P=0.419$; $\geq 12 \mathrm{wk}, P=0.147)$, frequency of exercise per week ( $\leq 3$ times/wk, $P=0.435$; $>3$ times/wk, $P=0.165$ ), and duration of session ( $<60 \mathrm{~min} / \mathrm{session}, P=0.141 ; \geq 60 \mathrm{~min} /$ session, $P=0.303$ ) did not significantly influence the effect of exercise on CRP levels (Figure 3).

\section{Risk of Bias Results}

Among the included studies, most (11,13-20) satisfied more than $50 \%$ of the quality criteria (four or more quality criteria) (Table 1). Of the nine studies, five clearly described and adequately completed the randomization process $(13,14,16,19,20)$. Eligibility criteria were specified in the majority of studies (eight out of nine) (11,13-16,18-20) while all studies adequately reported similarities in primary outcomes at baseline. Assessor blinding was reported in three studies $(13,14,19)$. Care provider and patient blinding were not reported in any studies. Point estimates and measures of variability presented for the primary outcome measures were reported in all studies. Finally, only two studies reported data for primary outcomes that were analyzed following the intention to treat principle $(13,14)$.

\section{Secondary Outcomes, Publication Bias, and Sensitivity Analysis}

The results showed a statistically significant reduction for weight (WMD $=-3.12 \mathrm{~kg} ; 95 \% \mathrm{CI}:-4.38$ to $-1.36 ; P<0.001$ ) and fasting insulin (WMD $=-2.15 \mu \mathrm{U} / \mathrm{ml} ; 95 \% \mathrm{CI}:-2.91$ to $-1.40 ; P<0.001$ ), but not in body fat percentage. However, meta-regression analyses reported no statistically significant relationship between change in CRP and weight or insulin (weight: $R^{2}=0.058, P=0.501$; insulin: $R^{2}=0.032, P=0.314$ ). With regard to publication bias, the Egger's test $(P=0.489)$ and the funnel plot (Figure 4) suggest that the mean effect of exercise training on CRP was not subject to publication bias. Finally, in the sensitivity analysis, with each study removed from the model individually, the results remained constant with not statistically significant changes across deletions.

\begin{tabular}{|c|c|c|c|c|}
\hline Study & $n$ & Favors exercise & Favors control & WMD $(95 \% \mathrm{Cl})$ \\
\hline Alberga et al. (13) & 148 & & & $-0.10(-0.93,0.73)$ \\
\hline Farpour-Lambert et al. (14) & 44 & & & $0.00(-3.38,3.38)$ \\
\hline Kelly et al. (11) & 19 & & & $1.60(-3.17,6.37)$ \\
\hline Kim et al. (15) & 26 & & & $-1.90(-2.38,-1.42)$ \\
\hline Meyer et al. (16) & 67 & & & $-1.50(-3.92,0.92)$ \\
\hline Murphy et al. (17) & 35 & & & $-0.60(-4.28,3.08)$ \\
\hline Part et al. (18) & 44 & & & $-0.40(-0.87,0.07)$ \\
\hline Vasconcellos et al. (19) & 20 & & & $-0.80(-2.91,1.32)$ \\
\hline Wong et al. (20) & 24 & & & $0.10(-2.98,3.18)$ \\
\hline \multirow{2}{*}{$\begin{array}{l}\text { Test for heterogeneity: } d f=8(P=0.001) ; I^{2}=69 \% \\
\text { Test for overall effect: } Z=-1.76(P=0.077)\end{array}$} & 427 & & & $-0.72(-1.52,0.08)$ \\
\hline & & $-3.00-1.50$ & 1.50 & \\
\hline
\end{tabular}

Figure 2. The effects of the exercise programs on C-reactive protein ( $\mathrm{mg} / \mathrm{l})$. Squares represent individual studies, and horizontal lines represent $95 \%$ confidence limits for individual studies. The diamond represents pooled WMD. Cl, confidence interval; WMD, weighted mean difference. 


\begin{tabular}{|c|c|c|c|c|}
\hline Subgroup analysis & $n$ (subjects) & Favors exercise & Favors control & WMD $(95 \% \mathrm{Cl})$ \\
\hline \multicolumn{5}{|l|}{ Weight status } \\
\hline Overweight & 54 & & & $0.22(-2.69,3.14)$ \\
\hline Obese & 373 & & - & $-0.79(-1.63,0.16)$ \\
\hline \multicolumn{5}{|l|}{ Ages } \\
\hline Children & 170 & & & $-0.66(-2.17,0.85)$ \\
\hline Adolescents & 257 & & & $-0.73(-1.73,0.26)$ \\
\hline \multicolumn{5}{|l|}{ Duration of studies } \\
\hline$<12$ wk & 45 & & & $-0.98(-3.99,2.03)$ \\
\hline$\geq 12 \mathrm{wk}$ & 382 & & - & $-0.36(-0.75,0.13)$ \\
\hline \multicolumn{5}{|l|}{ Session frequency } \\
\hline$\leq 3$ times/wk & 303 & & & $-0.28(-0.98,0.42)$ \\
\hline$>3$ times/wk & 124 & & & $-0.92(-2.22,0.38)$ \\
\hline \multicolumn{5}{|l|}{ Duration of session } \\
\hline$<60 \min$ & 272 & & & $-0.71(-1.76,0.34)$ \\
\hline$\geq 60 \mathrm{~min}$ & 155 & & & $-0.72(-2.03,0.58)$ \\
\hline & & -0.50 & 0.50 & \\
\hline
\end{tabular}

Figure 3. Subgroup analysis for the posttreatment. Squares represent pooled WMD for each subgroup analysis. Cl, confidence interval; WMD, weighted mean difference.

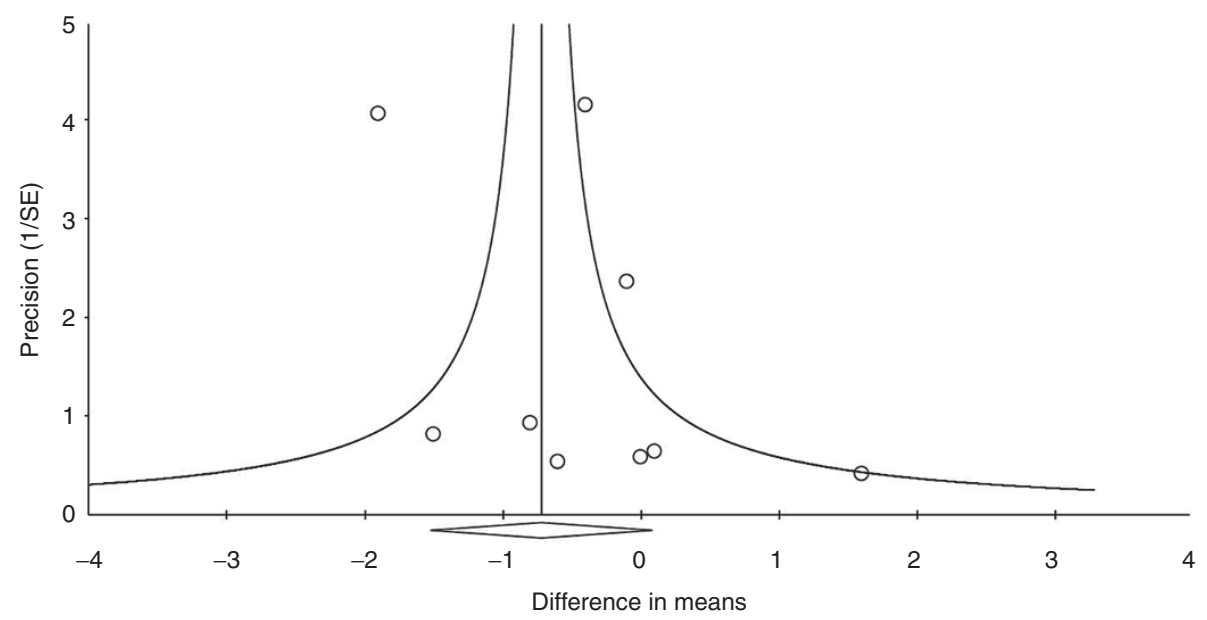

Figure 4. Funnel plot of precision by difference in means. Circles represent weighted mean difference for each study and the diamond represents pooled weighted mean difference.

\section{DISCUSSION}

The present study is the first meta-analysis to analyze the evidence for the effectiveness of exercise programs on CRP in children and adolescents with excess weight. Overall, changes in CRP were not quite statistically significant, although there were a trend toward reduction. Also, there were not significant moderators of exercise effects on CRP.

Physical exercise reduces CRP levels by multiple mechanisms, including a decrease in cytokine production by adipose tissue, improved endothelial function and insulin sensitivity, and possibly an antioxidant effect (10), among other factors. Also, the impact of exercise on inflammation in populations with excess weight is controversial and how exercise training reduces inflammation and decreases CRP levels is not well defined. While various studies show that exercise reduces inflammation, specifically CRP (22-24), other studies found no change in this parameter $(25,26)$. In this regard, the present meta-analysis is consistent with findings of recent studies in which exercise seemed not reduce levels of CRP after exercise intervention in obese youths. Also, although there was a nonsignificant trend reduction, the overall mean CRP level was
$2.81 \pm 1.34 \mathrm{mg} / 1$ (posttest) (Figure 2), still considered a moderate risk category (values of less than 1.0, 1.0-3.0, and more than $3.0 \mathrm{mg} / \mathrm{l}$ correspond to relative risk categories of low, moderate, and high, respectively) (27). On the other hand, weight losses were associated with improvements in CVD (hypertension, dyslipidemia, and insulin resistance index) (28) and inflammatory markers (CRP and adiponectin level) (3). Different RCT included in this meta-analysis had significant reductions in weight of between 2.5 and $6.1 \%(-8.2$ to $-2.9 \mathrm{~kg}$ ), although that may not be enough to cause a clinically relevant reduction in CRP. Therefore, despite the changes in several related factors like weight and insulin resistance, higher CRP levels persist in more active youths in most studies even after adjustment (10).

All factors included in the subgroup analysis did not significantly modify the exercise effects on CRP levels. In contrast, previous meta-analyses in obese youths examined the influence of physical exercise programs on the fasting insulin and glucose (29) or resting blood pressure (30) and suggest larger effects in programs with more than three sessions per week or $>12$ wk in duration. The small number of youths and studies included in subgroup analysis could be explains the 


\section{Systematic Review}

nonsignificant effects. Most of the RCTs had small sample sizes (i.e., all of the studies except one (13) had a sample size <100). Therefore, additional research on this topic is needed, including longitudinal interventions in this population and taking into account the limitations observed in this meta-analysis.

In summary, our findings suggest a nonsignificant trend toward a reduction CRP levels in overweight and obese youths. Therefore, exercise interventions may weakly reduce the risk of metabolic and cardiovascular events on obese youths in later life.

Finally, the present meta-analysis had certain limitations. First, the number of RCT included was small, although their homogeneity is optimized by the stringency of the inclusion criteria. Second, there is inconsistency regarding to definitions of overweight and obesity. Third, most studies did not include information on major determinants of the CRP level (number of hours elapsed since the last meal or since exercise). Fourth, only one study (14) assessed the daily physical activity performed by the subjects (recall or accelerometer), even though this could affect the CRP results. Fifth, the large variations in the type of exercise performed in the interventions could influence CRP levels (31). Finally, several studies not provided important information like pubertal stage $(15,16,20)$, compliance $(11,15,16,19,20)$, and exercise intensity $(15-17,19)$, which might have a nonnegligible influence on these small cohorts.

\section{METHODS}

Preferred Reporting Items for Systematic Reviews and Meta-Analyses (PRISMA) guidelines was used (32). The Research Committee of the Health and Social Research Center of Castilla-La Mancha University approved the study. Since the Spanish Law for Human, the informed consent for meta-analysis is not necessary.

\section{Literature Search}

The electronic bibliographical databases screened included: CINAHL (1937 to 2 September 2015), Cochrane Central Register of Controlled Trials (CENTRAL) (2002 to 2 September 2015), EMBASE (1980 to 2 September 2015), ERIC (1966 to 2 September 2015), MEDLINE (1965 to 2 September 2015), PsycINFO (1987 to 2 September 2015), and Science Citation Index (1900 to 2 September 2015). Manual searches were made. First, five keyword categorical searches were conducted: (i) "exercise" or "physical activity"; (ii) "child" and "adolescent"; (iii) "obesity" and "overweight"; (iv) "inflammatory markers"; and (v) "C-reactive protein." Second, categories " $i$ " to " $v$ " were combined using "and," and duplicates were removed. All languages were accepted. The search was conducted from 1st to 9th of February 2015 and updated from 1st to 2nd of September 2015.

\section{Study Selection}

Studies were included in the meta-analysis if they met the following criteria: (i) subjects: children and adolescents (aged 6-18 y) diagnosed as overweight or obese; (ii) type of study: RCT, in which the control group received no type of physical exercise or dietary restriction intervention; (iii) type of intervention: physical exercise program (no nutritional intervention); and (iv) evaluation of CRP. The four criteria for inclusion were restrictive in order to achieve a smaller homogeneous sample of studies.

\section{Data Collection}

Two authors (A.G.-H. and J.M.S.) extracted the following data from each candidate article selected: (i) characteristics of subjects (number, age, sex, and overweight/obesity definitions); (ii) exercise program characteristics (type, duration, frequency, and intensity); (iii) assessment of primary outcome (CRP) and secondary outcomes (weight, body fat, and fasting insulin); and (iv) results (before and after intervention). Discrepancies between the two reviewers about study conditions were resolved by consensus with the third author (Y.E.).

\section{Assessment of Risk of Bias}

Risk of bias of the studies was evaluated using the Delphi List (33). Quality assessment was independently performed by two unblended reviewers (A.G.-H. and J.M.S.) and disagreements were solved by consensus or by a third reviewer (Y.E.).

\section{Statistical Analysis}

Primary and secondary outcomes. The meta-analysis was conducted using the statistical software Comprehensive Meta-Analysis Version 2.2. The primary outcome in the meta-analysis was changes in CRP, expressed in milligrams per liter $(\mathrm{mg} / \mathrm{l})$. The WMD was calculated as the sum of the differences between groups in the mean of the CRP variable from pre- to postintervention (34) in each study and pooled using the random-effects model (DerSimonian-Laird approach). Finally, we used meta-regression to examine the relationship between changes in CRP and changes in weight $(\mathrm{kg})$, body fat $(\%)$, and fasting insulin $(\mu \mathrm{U} / \mathrm{ml})$.

Heterogeneity assessment, publication bias, sensitivity and subgroup analysis. The heterogeneity of the studies was assessed using Cochran's Q-statistic applied to the WMD (35). The percentage of total variation across the studies due to heterogeneity was determined using $I^{2}$. Usually $I^{2}$ is considered small if $0 \leq I^{2} \leq 25 \%$, medium if $25 \%<I^{2} \leq 50 \%$, and large if $I^{2}>50 \%$ (21). In this regard, assessment of bias, the funnel plot, and the Egger test were used to examine publication bias (36). A level of less than 0.05 was used to determine if statistically significant publication bias might be present. For the sensitivity analysis, to determine the influence of each study on the overall results, each study was removed from the model once and the pooled analyses were conducted without this study in the model.

Subgroup moderator analyses were conducted to determine whether exercise effects differed according to weight status (overweight or obese), ages (children or adolescents), duration of study $(<12 \mathrm{wk}$ or $\geq 12 \mathrm{wk})$, frequency of exercise per week ( $\leq 3$ times/wk or $>3$ times/wk), and duration of session $(<60 \mathrm{~min} /$ session or $\geq 60 \mathrm{~min} / \mathrm{ses}-$ sion). Therefore, we performed a meta-analysis in subgroup defined with each criterion. Moderator effects were considered significant at $P$ $<0.1$. Also, independent samples $t$-test was performed to know differences between CRP changes according to these criteria used. Finally, it must be acknowledged that to compare studies including youth with different maturation stages can be problematic. Unfortunately, just a few studies have controlled the pubertal status and we used chronological age cutoff points. A similar grouping approach has previously been used in studies of obese children $(29,30,37)$.

\section{STATEMENT OF FINANCIAL SUPPORT}

During the completion of this paper, A.G.-H. was visiting researchers at the University of Castilla-La Mancha (Health and Social Research Center, Cuenca, Spain), and he was supported with grants awarded by Proyectos Basales y Vicerrectoría de Investigación, Desarrollo e Innovación" (Universidad de Santiago de Chile, USACH).

Disclosure: The authors declare that they have no conflicts of interest.

\section{REFERENCES}

1. Lobstein T, Baur L, Uauy R; IASO International Obesity Task Force. Obesity in children and young people: a crisis in public health. Obes Rev 2004;5:Suppl 1:4-104.

2. Han JC, Lawlor DA, Kimm SY. Childhood obesity. Lancet 2010;375:1737-48.

3. Tam CS, Clément K, Baur LA, Tordjman J. Obesity and low-grade inflammation: a paediatric perspective. Obes Rev 2010;11:118-26.

4. Ridker PM. Clinical application of C-reactive protein for cardiovascular disease detection and prevention. Circulation 2003;107:363-9.

5. Danesh J, Collins R, Appleby P, Peto R. Association of fibrinogen, C-reactive protein, albumin, or leukocyte count with coronary heart disease. JAMA 1998;279:1477-82. 


\section{CRP, exercise, and overweight youths}

6. Choi J, Joseph L, Pilote L. Obesity and C-reactive protein in various populations: a systematic review and meta-analysis. Obes Rev 2013;14: $232-44$.

7. Juonala M, Viikari JS, Rönnemaa T, Taittonen L, Marniemi J, Raitakari OT. Childhood C-reactive protein in predicting CRP and carotid intima-media thickness in adulthood: the Cardiovascular Risk in Young Finns Study. Arterioscler Thromb Vasc Biol 2006;26:1883-8.

8. Kelley GA, Kelley KS. Effects of aerobic exercise on C-reactive protein, body composition, and maximum oxygen consumption in adults: a metaanalysis of randomized controlled trials. Metabolism 2006;55:1500-7.

9. Haskell WL, Lee IM, Pate RR, et al. Physical activity and public health: updated recommendation for adults from the American College of Sports Medicine and the American Heart Association. Med Sci Sports Exerc 2007;39:1423-34.

10. Kasapis C, Thompson PD. The effects of physical activity on serum C-reactive protein and inflammatory markers: a systematic review. J Am Coll Cardiol 2005;45:1563-9.

11. Kelly AS, Wetzsteon RJ, Kaiser DR, Steinberger J, Bank AJ, Dengel DR. Inflammation, insulin, and endothelial function in overweight children and adolescents: the role of exercise. J Pediatr 2004;145:731-6.

12. Hayashino Y, Jackson JL, Hirata T, et al. Effects of exercise on C-reactive protein, inflammatory cytokine and adipokine in patients with type 2 diabetes: a meta-analysis of randomized controlled trials. Metabolism 2014;63:431-40.

13. Alberga AS, Prud'homme D, Kenny GP, et al. Effects of aerobic and resistance training on abdominal fat, apolipoproteins and high-sensitivity C-reactive protein in adolescents with obesity: the HEARTY randomized clinical trial. Int J Obes (Lond) 2015;39:1494-500.

14. Farpour-Lambert NJ, Aggoun Y, Marchand LM, Martin XE, Herrmann FR, Beghetti M. Physical activity reduces systemic blood pressure and improves early markers of atherosclerosis in pre-pubertal obese children. J Am Coll Cardiol 2009;54:2396-406.

15. Kim ES, Im JA, Kim KC, et al. Improved insulin sensitivity and adiponectin level after exercise training in obese Korean youth. Obesity (Silver Spring) 2007;15:3023-30.

16. Meyer AA, Kundt G, Lenschow U, Schuff-Werner P, Kienast W. Improvement of early vascular changes and cardiovascular risk factors in obese children after a six-month exercise program. J Am Coll Cardiol 2006;48: 1865-70.

17. Murphy EC, Carson L, Neal W, Baylis C, Donley D, Yeater R. Effects of an exercise intervention using Dance Dance Revolution on endothelial function and other risk factors in overweight children. Int J Pediatr Obes 2009;4:205-14.

18. Park TG, Hong HR, Lee J, Kang HS. Lifestyle plus exercise intervention improves metabolic syndrome markers without change in adiponectin in obese girls. Ann Nutr Metab 2007;51:197-203.

19. Vasconcellos F, Seabra A, Cunha F, et al. Health markers in obese adolescents improved by a 12-week recreational soccer program: a randomised controlled trial. J Sports Sci 2015; e-pub ahead of print 24 July 2015.

20. Wong PC, Chia MY, Tsou IY, et al. Effects of a 12-week exercise training programme on aerobic fitness, body composition, blood lipids and C-reactive protein in adolescents with obesity. Ann Acad Med Singapore 2008;37:286-93.
21. Higgins JP, Thompson SG. Quantifying heterogeneity in a meta-analysis. Stat Med 2002;21:1539-58.

22. Reinehr T, Stoffel-Wagner B, Roth CL, Andler W. High-sensitive C-reactive protein, tumor necrosis factor alpha, and cardiovascular risk factors before and after weight loss in obese children. Metabolism 2005;54:1155-61.

23. Balagopal P, George D, Patton N, et al. Lifestyle-only intervention attenuates the inflammatory state associated with obesity: a randomized controlled study in adolescents. J Pediatr 2005;146:342-8.

24. Tsang TW, Kohn M, Chow CM, Singh MF. A randomized controlled trial of Kung Fu training for metabolic health in overweight/obese adolescents: the "martial fitness" study. J Pediatr Endocrinol Metab 2009;22:595-607.

25. Nassis GP, Papantakou K, Skenderi K, et al. Aerobic exercise training improves insulin sensitivity without changes in body weight, body fat, adiponectin, and inflammatory markers in overweight and obese girls. Metabolism 2005;54:1472-9.

26. Barbeau P, Litaker MS, Woods KF, et al. Hemostatic and inflammatory markers in obese youths: effects of exercise and adiposity. J Pediatr 2002;141:415-20.

27. Pearson TA, Mensah GA, Alexander RW, et al.; Centers for Disease Control and Prevention; American Heart Association. Markers of inflammation and cardiovascular disease: application to clinical and public health practice: a statement for healthcare professionals from the Centers for Disease Control and Prevention and the American Heart Association. Circulation 2003;107:499-511.

28. Reinehr T, Kiess W, Kapellen T, Andler W. Insulin sensitivity among obese children and adolescents, according to degree of weight loss. Pediatrics 2004;114:1569-73.

29. García-Hermoso A, Saavedra JM, Escalante Y, Sánchez-López M, Martínez-Vizcaíno V. Aerobic exercise reduces insulin resistance markers in obese youth: a meta-analysis of randomized controlled trials. Eur J Endocrinol 2014;171:163-71.

30. García-Hermoso A, Saavedra JM, Escalante Y. Effects of exercise on resting blood pressure in obese children: a meta-analysis of randomized controlled trials. Obes Rev 2013;14:919-28.

31. King DE, Carek P, Mainous AG 3rd, Pearson WS. Inflammatory markers and exercise: differences related to exercise type. Med Sci Sports Exerc 2003;35:575-81.

32. Liberati A, Altman DG, Tetzlaff J, et al. The PRISMA statement for reporting systematic reviews and meta-analyses of studies that evaluate health care interventions: explanation and elaboration. PLoS Med 2009;6:e1000100.

33. Verhagen AP, de Vet HC, de Bie RA, et al. The Delphi list: a criteria list for quality assessment of randomized clinical trials for conducting systematic reviews developed by Delphi consensus. J Clin Epidemiol 1998;51: 1235-41.

34. Morris SB. Estimating effect sizes from the pretest-posttest-control group designs. Organ Res Method 2007;11:364-86.

35. Higgins JP, Thompson SG, Deeks JJ, Altman DG. Measuring inconsistency in meta-analyses. BMJ 2003;327:557-60.

36. Egger M, Davey Smith G, Schneider M, Minder C. Bias in meta-analysis detected by a simple, graphical test. BMJ 1997;315:629-34.

37. Escalante Y, Saavedra JM, García-Hermoso A, Domínguez AM. Improvement of the lipid profile with exercise in obese children: a systematic review. Prev Med 2012;54:293-301. 